\title{
Chapter 19 \\ Mainstreaming Life Cycle Sustainability \\ Management in Rapidly Growing and Emerging Economies Through Capacity-Building
}

\author{
Sonia Valdivia, Sanjeevan Bajaj, Guido Sonnemann, Ana Quiros, \\ and Cassia Maria Lie Ugaya
}

\begin{abstract}
Professionals in companies in industrialised countries as well as consultants and academics working for these companies have acquired capabilities in life cycle sustainability management (LCSM). Actors in emerging economies are beginning to develop those capacities as well, supported by training programmes. This chapter highlights the work of the UNEP/SETAC Life Cycle Initiative which has worked toward strengthening LCSM/LCA capacities worldwide since its creation in 2002; presents the current conditions for mainstreaming LCSM following an analysis of available knowledge and infrastructure in 18 rapidly growing economies (including least developed countries, rapidly growing and emerging economies) based on four criteria; and discusses the results and proposes a framework to develop LCSM capacities and provides conclusions and an outlook with recommendations. As some capacities in a number of emerging economies are beginning to consolidate, the implementation and changes of current practices toward improved performance by implementing LCSM remain insufficient.
\end{abstract}

Keywords 10YFP Consumer Information Program (CIP) • Decision making • Life cycle assessment $\bullet$ Developing countries $\bullet$ Life cycle management $\bullet$ Life cycle

S. Valdivia $(\bowtie)$

World Resources Forum, St. Gallen, Switzerland

e-mail: sonia.valdivia@wrforum.org

S. Bajaj

Federation of Indian Chambers of Commerce \& Industry, New Delhi, India

G. Sonnemann

University of Bordeaux, Bordeaux, France

A. Quiros

Association for Life Cycle Assessment in Latin America (ALCALA), San Jose, Costa Rica

C.M.L. Ugaya

Universidade Tecnológica Federal do Paraná (UTFPR), Curitiba, Brazil

(C) The Author(s) 2015

G. Sonnemann, M. Margni (eds.), Life Cycle Management,

LCA Compendium - The Complete World of Life Cycle Assessment,

DOI 10.1007/978-94-017-7221-1_19 
sustainability assessment $\bullet$ Life cycle sustainability management $\bullet$ Sustainability $\bullet$ Sustainable Lifestyles and Education Program $\bullet$ UNEP/SETAC life cycle initiative

\section{Introduction}

Access to (elementary) education is a human right and technical and professional education shall be made generally available and equally accessible to all according to article 26 of the Universal Declaration of Human Rights (UN 1948). Education is also a fundamental determinant not only of health, demographic trends and individual income, but also of a country's aggregate level of economic growth (IIASA 2008) and thus provides the most promising route toward sustainable development.

Furthermore, the authors consider that education at all levels - from primary school via university to lifelong learning - is crucial to improving the understanding and minimization of environmental and socio-economic impacts. Thus, further promotion of life cycle sustainability management (LCSM) - which follows a holistic approach for better informed decisions - is paramount.

LCSM is a powerful approach that has been recognized by multinational companies for the last decade. It helps to structure decision-making processes to follow a life cycle perspective in business and industry across an ever-increasing number of organisations in industrialized countries.

In response to the need for improved understanding and technical skills on LCSM, a number of life cycle-focused initiatives worldwide have incorporated capacity-building in their missions. ${ }^{1}$ To illustrate this development, it is worth highlighting the work of the UNEP/SETAC Life Cycle Initiative. It establishes the strengthening of LCSM/LCA capacities worldwide. Since its creation in 2002, more than 30 training events in about 18 developing countries (Sonnemann et al. 2015) have been organized, not to forget the support of the life cycle management (LCM) capability maturity model (CMM) implementation in developing countries between 2012 and 2013 (Swarr et al. 2015a, b).

In 2014, important developments at the international level include the launch of two global programmes under the 10-Year Framework of Programs (10YFP), which cover consumer information, education and awareness-raising on life cycle-based approaches $^{2}$ (10YFP 2015):

- The 10YFP Consumer Information Program (CIP) is defined as a range of tools and systems that seek to encourage consumers for more sustainable choices about goods and services, including their use and end-of-life phases (CIP 2015).

- The Sustainable Lifestyles and Education Program (SLE) seeks

\footnotetext{
${ }^{1}$ The term "capabilities" is used for individuals and "capacities" for organizations as it is more institutional.

${ }^{2}$ In the context of the 10YFP, life cycle approaches also include life cycle management.
} 
- To develop sustainable ways of living common practice through overall systems change

- To promote demand for and enable use of sustainable infrastructures (e.g. related to transportation)

- To achieve well-being and improve quality of life for all through awarenessraising, education and capacity-building across all sectors of society (SLE 2015)

Capabilities on LCSM have been acquired by professionals in companies in industrialized countries as well as consultants and academics working for these companies. Actors in emerging economies are beginning to develop those capacities as well, supported by training programmes like the CMM implementation in developing countries between 2012 and 2013 (Swarr et al. 2015a, b). While local capacities are now available in the developing world, especially in rapidly growing and emerging economies, the implementation and changes of current practices toward improved performance is still insufficient (Valdivia et al. 2014; Sonnemann et al. 2015). This chapter seeks to present the current conditions for mainstreaming LCSM based on an analysis of available knowledge and infrastructure on life cycle approaches in 18 selected rapidly growing and emerging economies based on four criteria. ${ }^{3}$ Furthermore, the chapter aims to discuss the results, propose a framework to develop LCSM capacities and provide conclusions and an outlook with recommendations.

\section{Potential for Mainstreaming Life Cycle Sustainability Management in Developing Countries: A Global Status Assessment}

The term "mainstream" can be understood as "ideas, attitudes, or activities that are shared by most people and regarded as normal or conventional" (Oxford Dictionaries 2015) or as "products and services readily available and appealing to the general public, as opposed to being of interest only to a very specific subset of the public" (Business Dictionary 2015). The authors acknowledge that the connotation of mainstreaming can be negative if the ideas, attitudes, products or activities ignore the individual and group values that are essential in free societies or, in a broader sense, that become obstacles in a path toward sustainable development. In order to reach substantial socio-economic changes in societies, mainstreaming is a key instrument, but cultural diversity and different backgrounds need to be taken into account before designing and implementing measures.

To illustrate the existence of different mainstreaming perceptions in a country and the ways to implement changes, the case of India is described as follows.

\footnotetext{
${ }^{3}$ (a) training activities in place, (b) local LCA studies available, (c) national LCA databases in place, (d.1) an active national network and aspects such as (d.2) size of the network and (d.3) gender balance.
} 
In India, value systems that discourage non-conventional behavior are still "mainstream", but this is changing as being conventional and as weak and conformist. A need for mainstreaming social reform has been recognized in India and is being implemented through provisions in the Constitution and various laws. The social reform currently in place is questioning many traditional practices such as those perpetuating inequalities based on gender, caste or economic class. Although the social reform in India has legal support, substantial changes are still far behind.

While mainstreaming life cycle sustainability assessment (LCSM) in industrialized countries focuses on effective communication between opinion leaders and consumers on life cycle thinking, in developing countries it is capacity-building of companies and governments. Information-sharing platforms and demonstration projects are essential in developing countries.

\subsection{Methodology and Criteria for the Assessment of Mainstreaming Conditions}

The focus of the assessment of mainstreaming conditions concerns 18 rapidly growing and emerging economies that were selected according to geographical balance (Table 19.1).

Aside from gender, the criteria used to assess the mainstreaming conditions status of LCSM/LCA were inspired by the survey from AIST (2006) to analyze the situation of LCA implementation in selected countries, including Brazil, Malaysia and Australia. The following criteria were applied:

(a) LCM and LCA training activities in place. Results in Table 19.1 are interpreted as follows: 0 is equal to "not at all"; 1 to "only on LCA"; 2 to "multiple on LCM/LCA"; and 3 to "many good quality ones on LCM/LCA".

(b) LCA studies available. This implies that local data exist and that organisations start to implement LCSM. The scores have the following interpretations: 0: not at all; 1: few studies; 2: some, mainly by academics; and 3: many, by academics and big companies.

(c) National LCA database operating. This is the basic infrastructure needed to have the potential to mainstream LCSM. Three cases are considered: 0 : there is no database; 1: a database is under development; and 2: local database is available for core sectors in the country.

(d) Active national life cycle network(s), including information on size of the network and gender balance aspects (Buckingham-Hatfield 2002). In general, these networks can function as a major multiplier for applications of LCSM by organisation. The first part (d.1) indicates the existence ("1") or not ("0") of a network in the country; $0 / 1$ means that there is neither agreement on the existence of a network nor a website available. The second part (d.2) refers to the size of the network and the last part (d.3) to the percentage of women. 
Table 19.1 Mainstreaming conditions criteria in selected rapidly growing and emerging countries (a-d.3) and status of the market for LCA professionals (e)

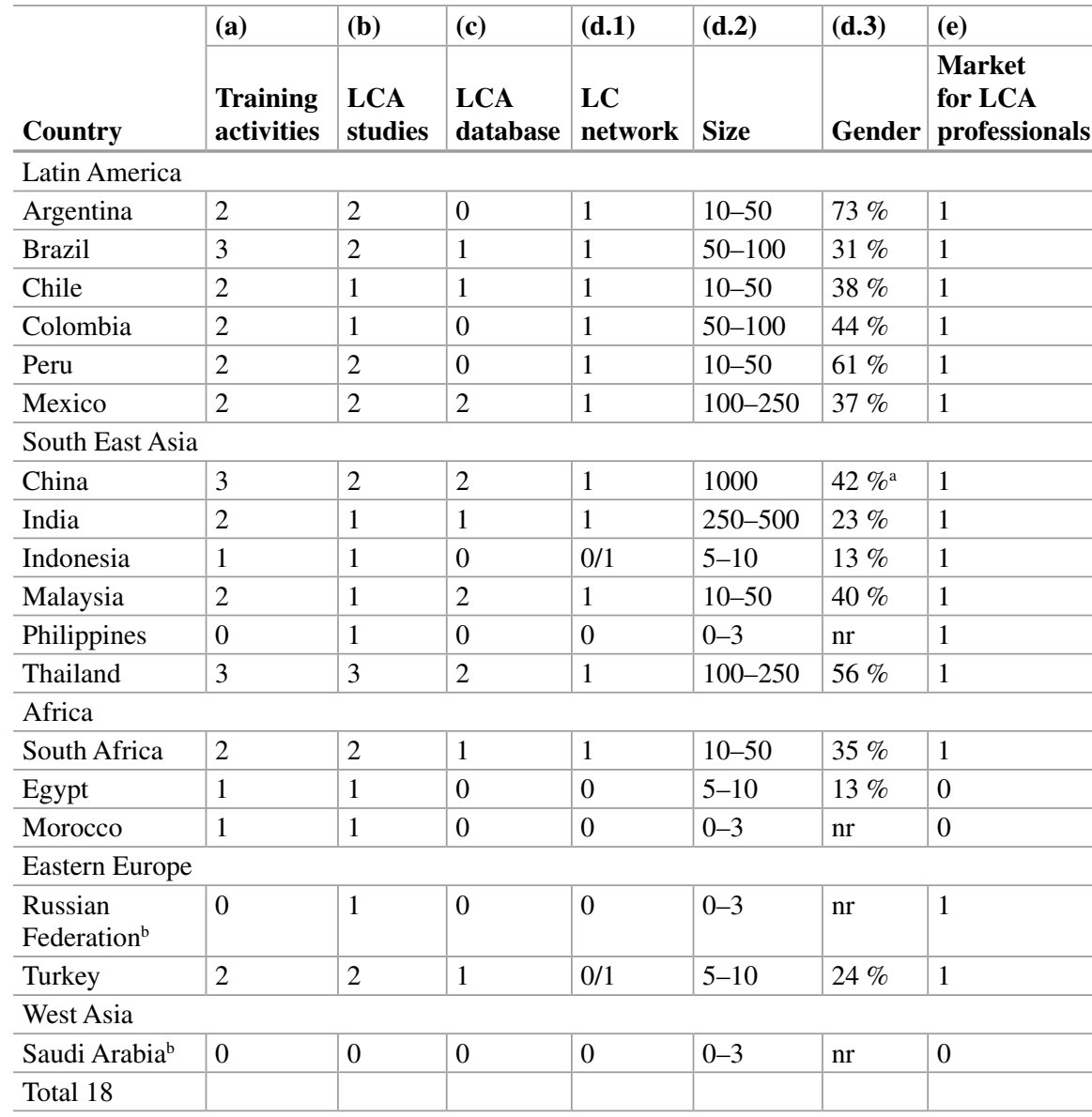

$n r$ not representative. No more than three persons have been identified in that country; hence, the result cannot be considered representative

anfo estimated by Ping Hou, China

${ }^{b}$ Only one response was received from this country; hence, the results cannot be considered valid

(e) A market for LCA professionals. In this case, an answer equal to 0 means there is no market at all, 1 means that the market is still developing and 2 means that the market is fully developed. The authors conclude that the existence of training activities, LCA studies, LCA databases and life cycle networks are conditions for mainstreaming.

Between 2013 and 2014, a global and a Latin American survey took place (Sonnemann et al. 2015; Valdivia et al. 2014), which were the basis for the assessment (see results in Table 19.1). About 80 responses were received from the life 
cycle national networks. Gender was analyzed based on the 2000 followers of the UNEP/SETAC Life Cycle Initiative. A discussion of the main findings is presented in the next sections.

The analysis of progress in the use of LCA in policies (see Sect. 2.7) could not be completed, due to insufficient information. Nevertheless, Sect. 2.7.1 on "LCA in policies" illustrates the situation in Thailand, China, Brazil and Mexico.

\subsection{Capacity-Building for Life Cycle Sustainability Management}

Capacity-building for LCSM means a process of building (i) capabilities to use the range of LCSM topics (see Fig. 19.2), (ii) relationships among key stakeholders and users and (iii) awareness-raising on the importance of a holistic life cycle perspective covering social, economic and environmental aspects in decision-making. Training is just one element of the capacity-building process, which usually focuses on providing skills for a specific problem (e.g. by learning how to generate LC data or to use LCA software).

However, as can be seen from the example India, it does not make sense to provide technical training if the managers are not convinced that LCSM is the way to tackle sustainable development challenges in organizations. Therefore, a package of training courses is needed, including LCM CMM and technical assistance for its implementation in developing countries, as done between 2012 and 2013 (Swarr et al. 2015a, b).

The parameters analyzed in 18 countries show that multiple training activities on both LCA and LCM, so in Thailand and Brazil, found a critical mass of experts to contribute to mainstreaming LCSM. A critical mass is developing, due to emerging efforts, in South Africa, Turkey, the other Latin American countries analyzed and the Asian countries except Indonesia and the Philippines. In the two latter countries, the level of LCA training activities is at a very early stage.

In Egypt, Morocco, Indonesia, the Philippines, the Russian Federation and Saudi Arabia, the offer of LCA and LCM training activities does not exist or is very limited. Consequently, mainstreaming LCSM cannot be envisaged in the short term, and the international community is asked for support in form of basic training activities.

\subsection{LCA Studies and LCA Databases}

The existence of LCA studies indicates the availability of local resources in terms of life cycle experts and tools and minimum funding to cover the costs of performing these studies. Subsequently, it also indicates the availability of some local foreground data, which can feed a national LCA database, so in China, Mexico, Malaysia and Thailand. 
Survey findings in the area of LCA studies and LCA databases (beyond the list of countries with a database) are presented below:

- In Brazil, Chile, India, South Africa and Turkey, a breakthrough is expected, as international organisations (e.g. UNEP and the European Commission jointly) or projects (the ecoinvent project on Internationalisation (www.sustainablerecycling.org)) as well as national organizations (e.g. Fundación Chile) are making progress with international and local resources.

- Colombia, Peru and Argentina are at an early stage of discussions on how to generate data and establish LCA databases (Quispe et al. 2014; see RPCV 2005).

- There is very little or no evidence of local LCA studies and no records at all concerning the development of databases in the remaining countries.

\subsection{Networking}

The survey results and additional literature sources confirm the existence of national life cycle networks in all countries covered by the survey, except Egypt, Morocco, Indonesia, the Philippines, the Russian Federation and Saudi Arabia. Where networks are operating, websites have been identified except in Turkey and Indonesia. A website helps to improve co-ordination and communication, and is a requirement for effective dissemination and communication.

The analysis of networking capacity is based not only on the amount of networks' members, but also on specific capacities measured as per the estimated number of life cycle practitioners per 10 million inhabitants in the country. 2014 population figures are used for these calculations (Worldometer 2014). The values presented in Table 19.2 range from 0.3 in Indonesia to 22 in Thailand. ${ }^{4}$ This result suggests that a critical condition for mainstreaming LCSM is the number of experts available in the country.

\subsection{Gender Aspects}

Gender equity is a pre-requisite for sustainable development (UNCED 1992).

The survey results in Table 19.2 show differentiated developments in countries where valid information is available. The average indicates a value of $40 \%$ female participation. Only in Thailand and Argentina did females comprise the majority. The figures were more balanced in Latin American countries, Malaysia and South Africa.

\footnotetext{
${ }^{4}$ The Russian Federation, Saudi Arabia and the Philippines were not considered in this part of the analysis, as the responses provided were not representative.
} 
Table 19.2 Mainstreaming status in selected rapidly growing and emerging countries (a-d.1) showing the number of LCA practitioners per 10 million inhabitants and gender distribution in life cycle networks

\begin{tabular}{l|c|l|l}
\hline Country & $\begin{array}{l}\text { \# of LCA practitioners } \\
\text { per 10 Mio inhabitants }\end{array}$ & $\begin{array}{l}\text { Proportion of } \\
\text { women } \mathbf{( \% )}\end{array}$ & $\begin{array}{l}\text { Mainstreaming conditions } \\
\text { (Total=a+b+c+d.1) [0-9] }\end{array}$ \\
\hline Thailand & 22 & 56 & 9 \\
\hline China & 7 & 42 & 8 \\
\hline Mexico & 11 & 37 & 7 \\
\hline Brazil & 4 & 31 & 7 \\
\hline Malaysia & 10 & 40 & 6 \\
\hline South Africa & 6 & 35 & 6 \\
\hline Argentina & 10 & 73 & 5 \\
\hline Peru & 7 & 39 & 5 \\
\hline Chile & 18 & 38 & 5 \\
\hline Colombia & 12 & 44 & 5 \\
\hline India & 2 & 23 & 5 \\
\hline Turkey & 4 & 24 & 4 \\
\hline Egypt & 1 & 13 & 2 \\
\hline Indonesia & 0.3 & 13 & 2 \\
\hline Philippines & $\mathrm{nr}$ & $\mathrm{nr}$ & 1 \\
\hline The Russian & $\mathrm{nr}$ & $\mathrm{nr}$ & 0 \\
\hline Federation & & & \\
\hline Morocco & $\mathrm{nr}$ & $\mathrm{nr}$ & 0 \\
\hline Saudi Arabia & $\mathrm{nr}$ & $\mathrm{nr}$ & 0 \\
\hline
\end{tabular}

$n r$ not representative. No more than three persons have been identified in that country; hence, the result cannot be considered representative

\subsection{Mainstreaming Conditions in Selected Countries}

While Thailand ranks the highest score (with a total of 9) and has very favourable conditions for mainstreaming, the respondents argue that the market is still under development. With $22 \mathrm{LC}$ practitioners per 10 million inhabitants, it is plausible that Thailand needs more capacity and experts to be able to cover the demand in more public policy areas and the private sector.

The conditions for mainstreaming LCSM in China, Mexico and Brazil, with scores of 7 or 8, are sufficient, but the fact that the market for LCA professionals is still relatively small suggests that the demand may need to be boosted by encouraging a strong uptake of LCSM within more industrial sectors and by enforcing current legislations or regulations. Expanding the number of LCA professionals per 10 million inhabitants in these countries, which rank below Thailand, is an urgent need in order to be able to grow with the market. This can be achieved, for instance, by having more universities provide education on LCA in natural science and engineering programs and on LCM in business schools and economic faculties. 
The next set of countries - South Africa, Malaysia, Argentina, Peru, Chile, Colombia, India and Turkey - with 4-6 points, have conditions for mainstreaming LCSM in the right direction. However, they still lack two essential ingredients: the business case for companies and the political will (e.g. to establish a national LCA database or create a policy requiring the use of LCA) through which progress is acknowledged and financial resources are made available. Without this push, the impact of efforts made by the UNEP/SETAC Life Cycle Initiative, national life cycle networks or other groups at the global and regional level will go unnoticed (UNEP/SETAC 2009a).

There is a last group of countries that has not yet developed mainstreaming conditions (scores from 0 to 2). These countries require tailored strategies and outreach approaches by taking into consideration their major challenges, in co-operation with key players in that country. Funding a core group of potential leaders in the life cycle area and a nationally-recognized organization like the Chambers of Commerce - take the example of the Federation of Indian Chambers of Commerce \& Industry (FICCI) in India - that can provide matching resources (e.g. experts' time, venues, etc.), is fundamental for any programme to be successful.

The survey results concerning the number of LCA practitioners per 10 million inhabitants, the proportion of women in life cycle networks and the overall rating regarding the conditions for mainstreaming LCSM are summarized in Fig. 19.1.

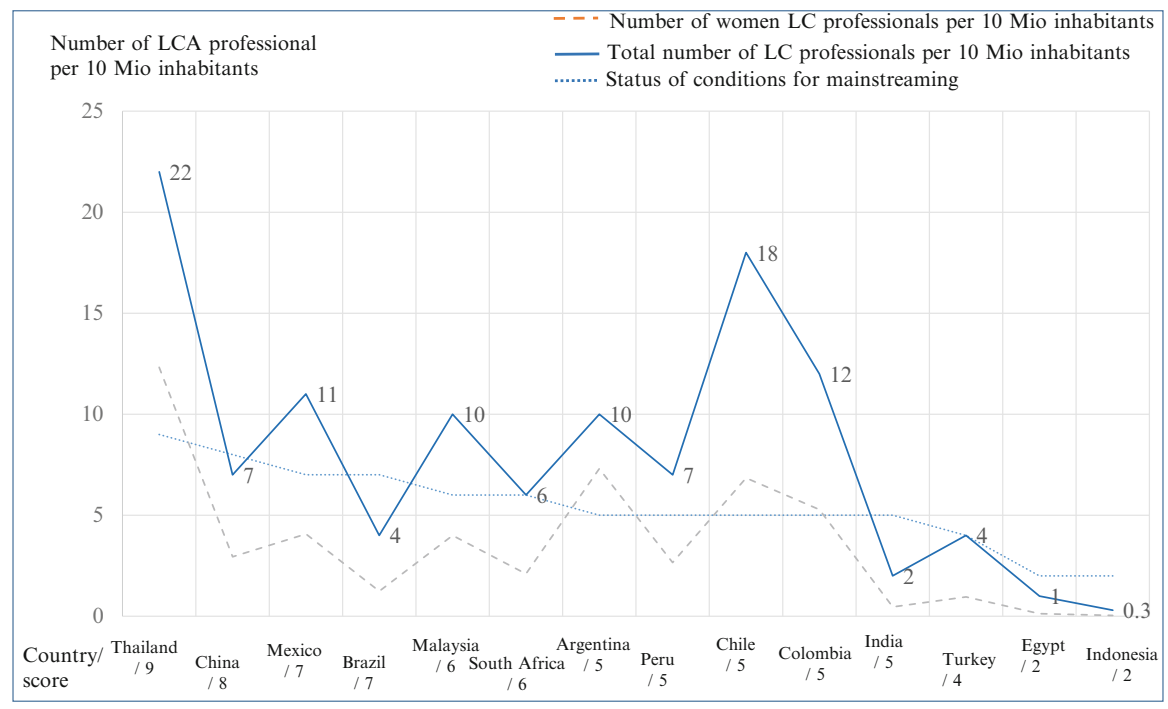

Fig. 19.1 LCA professionals per 10 million inhabitants vs. female participation and status of mainstreaming conditions 


\subsection{Market for LCA Professionals}

The existence of a market for LCA professionals is a positive development in the countries and constitutes the proof of mainstreaming. If there are already experts in a country contributing to developing life cycle tools or generating LCA data for policymaking or assisting companies, then there is a good basis to move toward a better understanding and managing the countries' and companies' value chains.

In the sample analyzed, all respondents indicate that, at best, the markets are under development even in countries with LCA databases and progress on the use of LCA in policies (e.g. Thailand, China, Mexico and Brazil, as introduced in Sect. 2.7.1). This finding shows that, despite efforts made in those countries, additional mechanisms are needed to boost the market substantially. Options include more university education on life cycle matters, professional training, life cycle innovation by companies and more public policies.

\subsubsection{Use of LCA in Policies}

Policies based on LCA were identified in two Asian and two Latin American countries. The general developments started in 2010. Asia, China and Thailand evidenced a significantly higher level of development and implementation of policies using LCA. The most encouraging policy in China, the Eco-design of Industrial Products Guidance of 2013 (MIIT/MEP/NRDC 2013), is boosting mainstreaming of LCA by promoting its use in product design. Thailand is using life cycle inventory data to quantify the Green Gross Domestic Product (GDP) of its industrial sectors, as well as LCA and Life Cycle Costing to assess Phase 1 (2008-2011) of the Thai Green Public Procurement Plan (ORDER PRE/116/2008 2008) to decide whether and how to implement phase 2 (2014-2017) (Thumrongrut Mungcharoen 2013).

More recent examples of the use of LCA in regulations and programs have been identified in Brazil and Mexico. These examples have not covered all industrial sectors yet. In Mexico, a regulation for sustainable buildings (NMX 2013) on criteria and minimum environmental requirements needs the impact assessment of the whole life cycle of buildings (including the use phase). In case of the replacement of building materials, it is also demanded the use of third-party reviewed LCAs of alternative materials for comparative assertion purposes (Güereca et al. 2015). As for Brazil, there is no mandatory policy regarding the use of LCA, but there are recommendations to use it, for example, in the Solid Wastes National Policy (Federal Law No. 12.305, 2010, and Decree No. 7.404, 2010, MMA 2010), which calls for shared responsibilities among relevant stakeholders along the life cycle of wastes and the use of LCA to promote products with fewer environmental impacts.

The cases presented above suggest an emerging awareness by politicians in emerging economies. It means that an increasing number of policy-makers is demanding LCA and information for decision-making at the product and sectorial levels. Evidently, this will contribute to creating favourable conditions for mainstreaming LCSM. 


\section{Framework for Capacity-Building and Developing Capabilities to Mainstream Life Cycle Sustainability Management}

Strengthening capacity-building and the development of capabilities to mainstream LCSM is a continual process and implies a step-by-step approach. A framework with the range of topics embraced by LCSM is presented in Fig. 19.2 and described below in this section.

The sequence is based on the flow of definitions and results that serve the next topic, but does not imply a fixed training sequence, except from LCM, which is recommended as the first training module because it introduces life cycle thinking and the various tools - not only LCA - and explains the way they could be articulated.

The tools covered have "continual improvement" as a central target message (see Fig. 19.2). If then there is an interest by an organization or an individual in environmental LCA (E-LCA according to ISO 14040/44 2006), further training on this tool can be provided. Other approaches, for which training could also be provided, include carbon, water and environmental footprinting, organizational LCA (O-LCA, UNEP/SETAC 2015b), hotspot analysis (Fava et al. 2014) as well as Social LCA (S-LCA, UNEP/SETAC 2009b), and Life Cycle Costing (LCC).

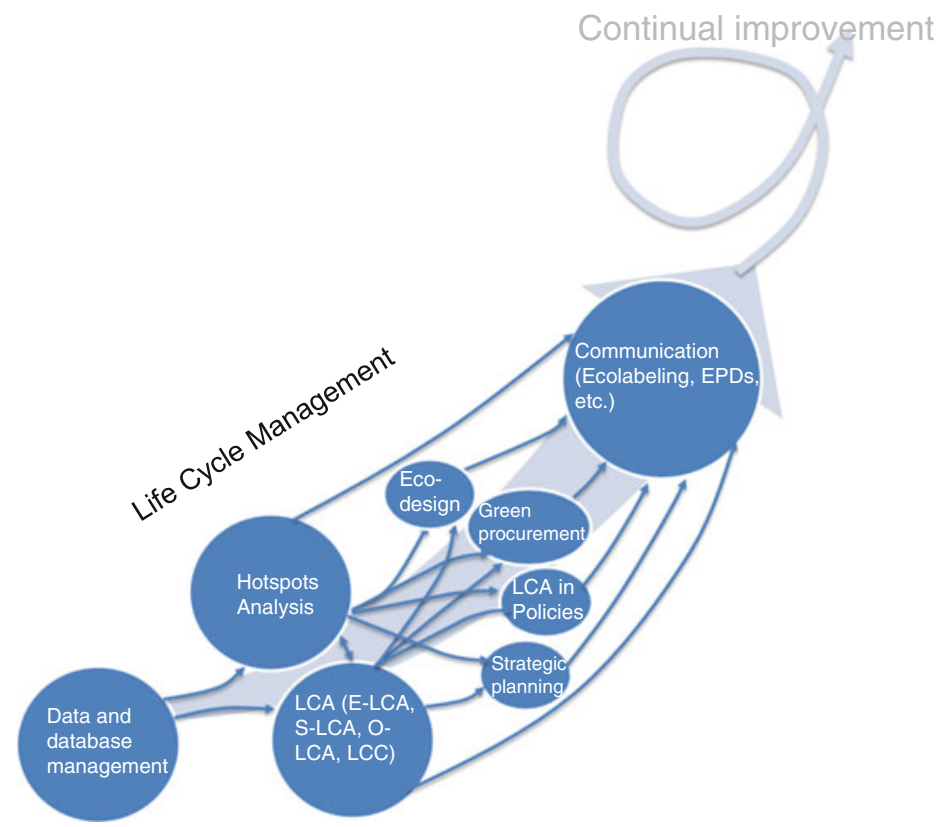

Fig. 19.2 Capacity-building and developing capabilities for mainstreaming LCSM 
Since LCSM needs life cycle information, the availability of reliable data is also important. Due to the enormous amount of data needed to perform an LCA study, capacity-building regarding data development and database management can be also of interest. In this sense, a training kit has been developed, based on the Global Guidance for LCA Databases (UNEP/SETAC 2011). Data, however, are not enough for understanding data formation; impact assessment models and further training on the review of the LCA of products are highly recommended to be able to interpret the results.

The improved understanding of impact assessment models and frameworks facilitates the interpretation of results and their use in design choices (eco-design), sustainable consumption (sustainable procurement), strategic planning in business and LCA in policies. Further skills and abilities are necessary for communicating sustainability performance, aiming at disseminating best practices and improvements while avoiding greenwashing.

The choice of the training path and whether or not a topic is considered in a capacity-building program depends on the needs of the audience and on country and company priorities. No matter the choice, the continual improvement of capacities should remain a focus.

\section{Conclusions, Recommendations and Outlook}

\subsection{Conclusions and Recommendations}

1. General progress since 2002 .

Countries have advanced since 2002, when none of them counted on a life cycle network or a LCA database (UNEP/SETAC 2015b). The authors recommend reinforcing the trend in the countries analyzed with continual capacity-building programs, financial support and technical assistance endorsed by national and local governments and facilitated by agencies for international co-operation and inter-governmental organizations.

2. LC networks as a success in capacity-building.

The authors' experiences confirm that national life cycle networks are key to successful capacity-building programs.

3. Insufficient number of LCA professionals in the country.

The number of LCA professionals in all countries is low in relation to the size of the population.

4. Gender distribution.

This indicator has not been sufficiently researched in the LCSM field. However, the respective findings of the current study are encouraging. In general, the higher the percentage of women, the better the score concerning the status of mainstreaming conditions. Only in two countries, Argentina and Thailand, did women represent the majority. 
5. Presence of LCA in policies.

The cases from Thailand, China, Mexico and Brazil reinforce the results of the status of mainstreaming condition assessment in which these countries rank in the top four. This shows that the use of LCA in policies is possible in emerging and rapidly growing economies.

6. Thailand with favourable LCSM/LCA mainstreaming conditions.

Of the 18 countries researched, Thailand excels in mainstreaming LCA, as it uses LCA-based results in policies on public procurement. However, the authors cannot conclude that LCSM is mainstream in this country. Nevertheless, the case of Thailand demonstrates how far a country with limited resources can go when strong political acceptance is given.

7. Countries with no conditions for mainstreaming.

Countries at the bottom of the ranking are in the position where the others were in 2002. The first step for them is to address awareness-raising events for decision-makers from business as well as municipal and national governments, and basic training for academia and consultants. Support from international organizations is key to assisting these countries in paving the way for the conditions in which mainstreaming LCSM can be envisaged.

\subsection{Outlook}

Capacity-building programs on LCA/LCM/LCSM are needed to intensify and deepen their activities on a greater pace and to connect them to global programs such as CIP and SLE.

Ongoing international co-operation as well as new forms of inter-regional cooperation are key to improving the conditions for mainstreaming LCSM (UNEP/ SETAC 2015b).

According to current experiences regarding capacity-building and capability development trends, LCM, followed by LCA and footprinting approaches as well as data and database management, appear to be the most sought-after areas of skills development. While LCA appeals more to academia and consultants, LCSM is at the core of what companies are interested in.

Echoing the reflections of Paul Hohnen (2014), more awareness from politicians is essential to boost implementation of LCA in developing countries. Additionally, streamlined communication is needed at all levels. The implementation of LCSM and the tools and data required can no longer be presented as a complicated or expensive approach, but rather as a valuable and powerful management way toward innovation as well smart and responsible decision-making for more sustainable consumption and production (Hohnen 2014). 
Acknowledgements The authors would like to thank the following for valuable feedback provided during the development of the study and writing of the report: Sohini Gupta (FICCI), David Cozac and Sandra Mendez (EMPA).

Disclaimer The views and opinions expressed in this chapter are those of the authors and do not necessarily reflect the views of their organizations.

Open Access This chapter is distributed under the terms of the Creative Commons Attribution Noncommercial License, which permits any noncommercial use, distribution, and reproduction in any medium, provided the original author(s) and source are credited.

\section{References}

10YFP (2015) 10-year framework of programmes on sustainable consumption and production. www.unep.org/10yfp/. Accessed 28 Feb 2015

AIST (2006) 5th AIST workshop on LCA for Asia Pacific Region: summary of country reports in Asia Pacific Region (incl. Australia, Brazil \& Chile). www.aist-riss.jp/old/lca/asianetwork/ symposium/report/2006/powerpoint/02sagisaka.pdf. Accessed 28 Feb 2015. ISO 14040/44 (2006) Environmental management - life cycle assessment - principles and framework. ISO. Geneva

Buckingham-Hatfield S (2002) Gender equality - a pre-requisite for sustainable development. Geography 87(3):227-233. www.jstor.org/discover/10.2307/40573738?sid=21105989898753 \&uid $=2490615183 \&$ uid $=2490615193 \&$ uid $=70 \&$ uid $=3 \&$ uid $=2134 \&$ uid $=60 \&$ uid $=2 \&$ uid=3737760. Accessed 28 Feb 2015

CIP (2015) The 10YFP consumer information program (CIP). www.unep.org/10yfp/Programmes/ ProgrammeConsultationandCurrentStatus/Consumerinformation/tabid/106265/Default.aspx. Accessed 28 Feb 2015

Fava et al (2014) Hotspots analysis: mapping of existing methodologies, tools and guidance and initial recommendations for the development of global guidance. www.lifecycleinitiative.org/ wp-content/uploads/2014/12/UNEP-Hotspots-Mapping-Project-Final-Report-Phase-1.pdf. Accessed 28 Feb 2015

Güereca PL, Ochoa R, Gilbert H, Suppen N (2015) Life cycle assessment in Mexico: overview of development and implementation. Int J Life Cycle Assess 20(3):311-317

Hohnen P (2014) Life cycle thinking and the next industrial revolution. The smarter business blog (in Theory). http://tobiaswebb.blogspot.in/2014/12/life-cycle-thinking-and-next-industrial. html. Accessed 28 Feb 2015

IIASA (2008) Economic growth in developing countries: education proves key. Policy Brief \# 3, International Institute of Applied Systems Analysis (IIASA). http://iussp2009.princeton.edu/ papers/92600. Accessed 28 Feb 2015

ISO 14040/44 (2006) Environmental management - life cycle assessment. Requirements and guidelines. ISO, Geneva

MIIT/MEP/NRDC (2013) Eco-design of industrial products guidance. Published in 2013 by the Ministry of Industry and Information Technology and the Ministry of Environmental Protection of the People's Republic of China, and the National Development of Reform Commission (NDRC). http://www.indigodev.com/sepa_eip_guideline.html. Accessed 28 Feb 2015

MMA (2010) Politica Nacional de Resíduos Sólidos - Ministério do Meio Ambiente. Lei no 12.305/2010, Decreto No. 7.404/2010. www.abdi.com.br/. Accessed 28 Feb 2015

NMX (2013) Norma Mexicana NMX-AA-164-SCFI-2013: Edificacion Sustentable - Criterios y Requerimientos Ambientales Minimos (Sustainable building - minimum environmental criteria and requirements). http://biblioteca.semarnat.gob.mx/janium/Documentos/Ciga/agenda/ DOFsr/DO3156.pdf. Accessed 28 Feb 2015 
ORDER PRE/116/2008 (2008) [Thai] Green public procurement plan of the state general administration and its public bodies, and the managing bodies of the social security. Published on 21 January. www.measures-odyssee-mure.eu/public/mure_pdf/transport/SPA44.PDF. Accessed $28 \mathrm{Feb} 2015$

Oxford Dictionaries (2015) Mainstream. www.oxforddictionaries.com/definition/english/mainstream. Accessed 28 Feb 2015

Quispe I, Santillan J, Valdivia S (2014) VI International conference on life cycle assessment in Latin America: CILCA 2015-Lima, Peru, July 13 to 16, 201. Int J Life Cycle Assess 19(3):718

RPCV (2005) Red Peruana de Ciclo de Vida. www.red.pucp.edu.pe/ciclodevida/. Accessed 28 Feb 2015

SLE (2015) The 10YFP sustainable lifestyles and education program. www.unep.org/10yfp/ Programmes/ProgrammeConsultationandCurrentStatus/Sustainablelifestylesandeducation/ tabid/106266/Default.aspx. Accessed 28 Feb 2015

Sonnemann G, Ciroth A, Valdivia S (2015) Opportunities for national life cycle networks creation and expansion around the world. Life-Cycle Initiative, United Nations Environment Programme and Society for Environmental Toxicology and Chemistry, Paris (in press)

Swarr et al (2015a) Building organizational capability for life cycle management. In: Sonnemann G, Margni M (eds) LCA compendium, book life cycle management. Springer, Dordrecht, pp 239-256

Swarr T et al (2015b) Building organizational capability for life cycle management. Int J Life Cycle Assess (in press)

Thumrongrut Mungcharoen (2013) LCA applications in Thailand. In: Proceedings of the 2014 Chinese conference on life cycle management (CLCM), Beijing (www.clcm.org.cn/). 2014

UN (1948) Universal declaration of human rights. http://www.un.org/en/documents/udhr/. Accessed 28 Feb 2015

UNCED (1992) United Nations conference on environment and development, 1992. 'Rio Declaration on Environment and Development' (Rio Declaration). Rio de Janeiro, 2012

UNEP/SETAC (2009a) LCM: how business uses it to decrease footprint, create opportunities and make value chains more sustainable. Paris

UNEP/SETAC (2009b) Guidelines for a social life cycle assessment. Paris

UNEP/SETAC (2011) Global guidance principles for LCA databases. Paris

UNEP/SETAC (2015a) UNEP/SETAC life cycle initiative. www.lifecycleinitiative.org. Accessed $28 \mathrm{Feb} 2015$

UNEP/SETAC (2015b) Organizational life cycle assessment - guidance for organizations to conduct LCA considering their value chain. Life-Cycle Initiative, United Nations Environment Programme and Society for Environmental Toxicology and Chemistry, Paris (in press)

Valdivia S, Mila I, Canals L (2014) A evolução do pensamento sobre Ciclos de Vida na América Latina. www.brasilpnuma.org.br/informativo/index_137.html. Accessed 28 Feb 2015

Worldometer (2014) Countries in the World. http://www.worldometers.info/world-population/ population-by-country/. Accessed 28 Feb 2015 